\title{
Enhanced Thermal Stability in Perovskite Solar Cells by Assembling 2D/3D Stacking Structures
}

\author{
Yun Lin, ${ }^{\dagger}$ Yang Bai, ${ }^{\dagger}$ Yanjun Fang, ${ }^{\dagger}$ Zhaolai Chen, ${ }^{\dagger}$ Shuang Yang, ${ }^{\dagger}$ Xiaopeng Zheng, ${ }^{\dagger}$ Shi Tang, ${ }^{\dagger}$ \\ Ye Liu, ${ }^{\dagger}$ Jingjing Zhao, ${ }^{\dagger}$ and Jinsong Huang ${ }^{*}{ }^{\dagger},+(0)$ \\ ${ }^{\dagger}$ Department of Mechanical and Materials Engineering, University of Nebraska-Lincoln, Lincoln, Nebraska 68588, United States \\ ${ }^{\ddagger}$ Department of Applied Physical Science, University of North Carolina, Chapel Hill, North Carolina 27514, United States
}

ABSTRACT: Two-dimensional (2D) perovskites have been shown to be more stable than their three-dimensional (3D) counterparts due to the protection of the organic ligands. Herein a method is introduced to form $2 D / 3 \mathrm{D}$ stacking structures by the reaction of $3 \mathrm{D}$ perovskite with $n$-Butylamine (BA). Different from regular treatment with $n$-Butylammonium iodide (BAI) where $2 \mathrm{D}$ perovskite with various layers form, the reaction of $\mathrm{BA}$ with $\mathrm{MAPbI}_{3}$ only produce $(\mathrm{BA})_{2} \mathrm{PbI}_{4}$, which has better protection due to more organic ligands in $(\mathrm{BA})_{2} \mathrm{PbI}_{4}$ than the mixture of $2 \mathrm{D}$ perovskites. Compared to BAI treatment, $\mathrm{BA}$ treatment results in smoother $2 \mathrm{D}$ perovskite layer on $3 \mathrm{D}$ perovskites with a better coverage. The photovoltaic devices with $2 \mathrm{D} / 3 \mathrm{D}$ stacking structures show much improved stability in comparison to their 3D counterparts when subjected to heat stress tests. Moreover, the conversion of defective surface into $2 \mathrm{D}$ layers also induces passivation of the $3 \mathrm{D}$ perovskites resulting in an enhanced efficiency.

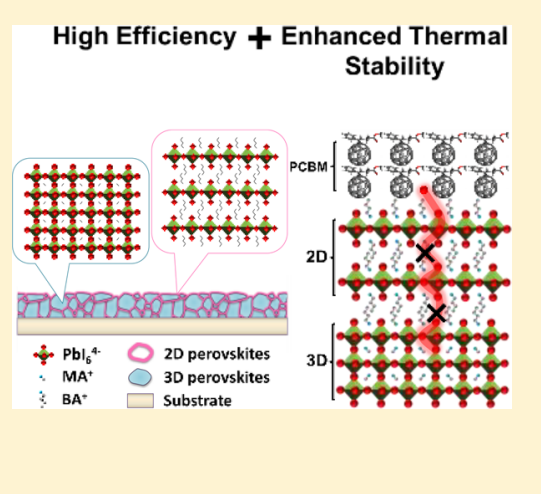

rganic-inorganic halide perovskites have become a class of promising materials in the optoelectronic fields of solar cells, ${ }^{1}$ light emitting diodes, ${ }^{2}$ photodetectors, ${ }^{3}$ and radiation detectors ${ }^{4}$ owing to their outstanding optoelectronic properties. $^{5-7}$ Three-dimensional perovskite polycrystalline thin films inevitably contain defects on surfaces and at grain boundaries, ${ }^{8,9}$ which can incur nonradiative charge recombination to reduce device efficiency and initiate the degradation of perovskites. $^{10-12}$ Therefore, passivation of defects is necessary, and a lot of related research has been done to continuously improve the photovoltaic performance and stability. ${ }^{10-20}$ The record power efficiency of perovskite solar cells has reached over $22.1 \%$. $^{21}$

Compared to $3 \mathrm{D}$ perovskites, enhanced moisture stability has been observed in $2 \mathrm{D}$ perovskite materials. ${ }^{22-26} 2 \mathrm{D}$ perovskites $(\mathrm{PEA})_{2}(\mathrm{MA})_{2} \mathrm{~Pb}_{3} \mathrm{I}_{10} \quad\left(\mathrm{PEA}=\mathrm{C}_{6} \mathrm{H}_{5}\left(\mathrm{CH}_{2}\right)_{2} \mathrm{NH}_{3}{ }^{+}, \mathrm{MA}=\right.$ $\mathrm{CH}_{3} \mathrm{NH}_{3}^{+}$) are used as absorbers in solar cells; the powder X-ray diffraction of $(\mathrm{PEA})_{2}(\mathrm{MA})_{2} \mathrm{~Pb}_{3} \mathrm{I}_{10}$ did not show obvious changes after exposure to $52 \%$ relative humidity for 46 days, while $\mathrm{MAPbI}_{3}$ completely converted to $\mathrm{PbI}_{2} \cdot{ }^{22} \mathrm{~A}$ similar result that a film of $(\mathrm{BA})_{2}(\mathrm{MA})_{2} \mathrm{~Pb}_{3} \mathrm{I}_{10}$ showed extremely high moisture stability was also reported. ${ }^{23}$ Despite high moisture stability, the efficiency of $2 \mathrm{D}$ perovskite solar cells is still quite low. The record power conversion efficiency (PCE) of 2D perovskite solar cells reported in the literature is $13.7 \% .^{27}$ In this sense, construction of $2 \mathrm{D} / 3 \mathrm{D}$ stacking structures can combine the advantages of enhanced stability in $2 \mathrm{D}$ perovskites as well as the strong light absorption and good charge carrier transport properties in $3 \mathrm{D}$ perovskite materials. On the basis of our previous work, degradation of perovskite films was initialized from the defects sites on surfaces and at grain boundaries. ${ }^{28}$ Therefore, introducing a thin $2 \mathrm{D}$ perovskite layer to wrap the surface and grain boundary of $3 \mathrm{D}$ perovskites is promising to enhance the device stability while maintaining its high efficiency.

In this work, we report the construction of $2 \mathrm{D} / 3 \mathrm{D}$ stacking structures by the reaction of $n$-butylamine (BA) with the surface of $3 \mathrm{D}$ perovskites. We found that the resulting $2 \mathrm{D}$ perovskite layers by two methods, i.e., BA and $n$-butylammonium iodide (BAI) treatments, had different compositions; therefore, the possible chemical reaction mechanisms are proposed. As a result, the introduction of a thin $2 \mathrm{D}$ perovskite layer on the surface and/or at the grain boundaries of $3 \mathrm{D}$ perovskites enhances the thermal stability of the finished photovoltaic devices. In addition, the thin $2 \mathrm{D}$ layers also have defect passivation and defect healing effects, which reduce the trap density, prolong the carrier lifetime, and increase the PCE to $19.56 \%$.

The schematic illustration of the $2 \mathrm{D} / 3 \mathrm{D}$ stacking structure is shown in Figure 1a. The one-step spin-coating method was employed to form polycrystalline $\mathrm{MAPbI}_{3}$ thin films. Then, in the following post-treatments, two kinds of solutions (BA dissolved in chlorobenzene (CB) and BAI dissolved in isopropyl alcohol (IPA)) were spun-coated on top of 3D perovskite layers. We expected that the BA or BAI molecules would gradually diffuse into the crystalline structure through surface and grain boundaries, reacting with $\mathrm{MAPbI}_{3}$ according to eqs 1 and 2

Received: October 10, 2017

Accepted: January 19, 2018

Published: January 19, 2018 


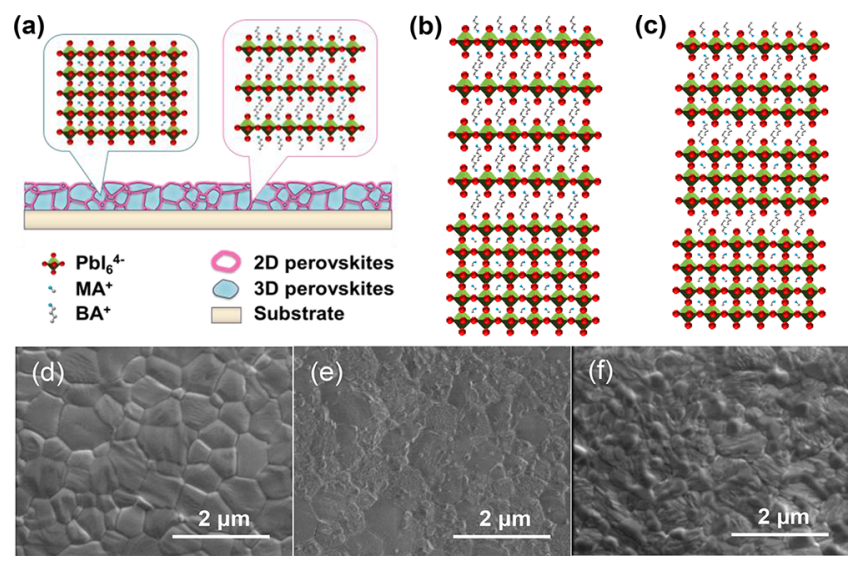

Figure 1. Schematic figure of (a) the perovskite film treated by BA to form a $2 \mathrm{D} / 3 \mathrm{D}$ stacking structure and $(\mathrm{b}, \mathrm{c}) 2 \mathrm{D} / 3 \mathrm{D}$ molecular junctions on the surface and at grain boundaries of $3 \mathrm{D}$ perovskite films induced by BA and BAI treatments, respectively; SEM images of (d) $\mathrm{MAPbI}_{3}$ films, (e) BA-treated $\mathrm{MAPbI}_{3}$ films, and (f) BAI-treated $\mathrm{MAPbI}_{3}$ films.

$$
\begin{aligned}
& 2 \mathrm{BA}+\mathrm{MAI}+\mathrm{MAPbI}_{3} \rightarrow(\mathrm{BA})_{2} \mathrm{PbI}_{4}+2 \mathrm{MA} \uparrow \\
& 2 \mathrm{BAI}+n \mathrm{MAPbI}_{3} \leftrightarrow(\mathrm{BA})_{2}(\mathrm{MA})_{n-1} \mathrm{~Pb}_{n} \mathrm{I}_{3 n+1}+\mathrm{MAI}
\end{aligned}
$$

As a result, thin layers of two-dimensional perovskites were generated on top of $3 \mathrm{D}$ perovskite polycrystalline films, forming the $2 \mathrm{D} / 3 \mathrm{D}$ stacking structures. The molecular structures of the formed $2 \mathrm{D}$ layers are different, as illustrated in Figure 1b,c.

Surface morphology changes of $\mathrm{MAPbI}_{3}$ films treated by BA and BAI with optimized solution concentrations (see below) were observed by scanning electron microscopy (SEM). The morphology of pristine $\mathrm{MAPbI}_{3}$ thin films in Figure 1d resembles that of typical perovskite films made by the one-step spin-coating method. After BA treatment, the surface became smoother (Figure 1e), which resembles the effect of amine gas treatment where the surfaces of perovskite films were dissolved by amine and re-formed after the amine evaporated. ${ }^{29}$ This smoother surface morphology indicates that the newly formed $2 \mathrm{D}$ perovskite layer can uniformly cover the $3 \mathrm{D}$ perovskites underneath. For BAI treatment, a clear surface morphology change was also observed (Figure 1f) where the surface was relatively rougher. This morphology change may be due to $3 \mathrm{D}$ to $2 \mathrm{D}$ phase transition. ${ }^{30}$ The RMS (root mean square) surface roughness values extracted from atomic force microscopy measurements (see Figure S1) reduce from $32.51 \mathrm{~nm}$ for pristine $\mathrm{MAPbI}_{3}$ films to 16.87 and $18.95 \mathrm{~nm}$ after BA and BAI treatments, respectively.

$\mathrm{XRD}$ and UV-vis absorption measurements were conducted to verify the formation of $2 \mathrm{D} / 3 \mathrm{D}$ stacking structure. The formed $2 \mathrm{D}$ perovskite layers are too thin to be detected in regular XRD and absorption measurements for the real posttreatment conditions used in the device fabrication; therefore, the post-treatment time for samples used here was intentionally prolonged. Figure $2 \mathrm{a}$ shows the XRD patterns of $\mathrm{MAPbI}_{3}$ polycrystalline thin films before and after BA or BAI treatment for $3 \mathrm{~min}$. The XRD pattern of pure 2D perovskite films with different $n$ values ( $n$ represents the number of $\mathrm{Pb}-\mathrm{I}$ sheets in each inorganic layer) can be found in a previous report. ${ }^{23}$ After BA treatment, some additional diffraction peaks showed up, which were indexed to be (002), (004), (006), and (008) planes of $2 \mathrm{D}$ perovskite $(\mathrm{BA})_{2} \mathrm{PbI}_{4}(n=1)$. The intensity of
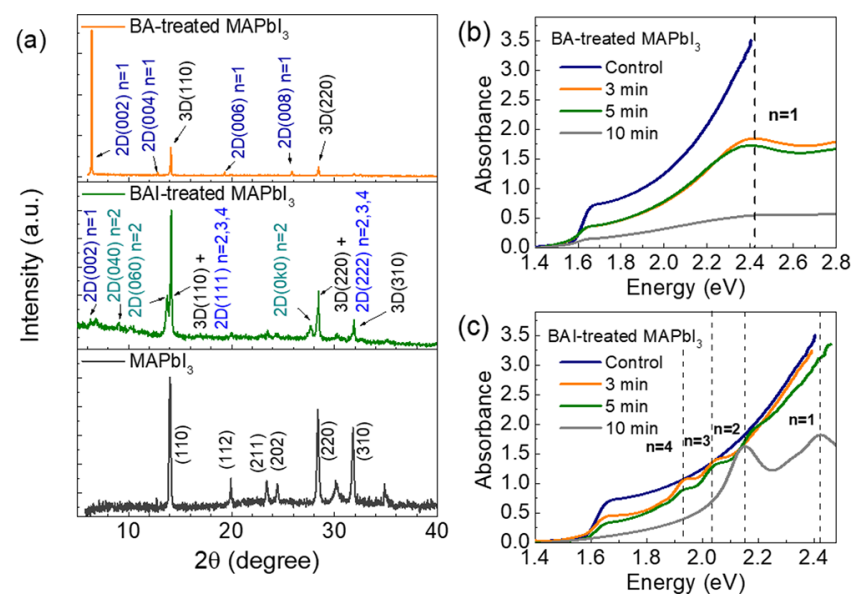

Figure 2. $\mathrm{XRD}$ of (a) BA-treated $\mathrm{MAPbI}_{3}$ films, BAI-treated $\mathrm{MAPbI}_{3}$ films, and the bottom $3 \mathrm{D} \mathrm{MAPbI}_{3}$ films. Absorption spectra of (b) BAtreated $\mathrm{MAPbI}_{3}$ films and (c) BAI-treated $\mathrm{MAPbI}_{3}$ films with different reaction times.

diffraction peaks of $(\mathrm{BA})_{2} \mathrm{PbI}_{4}$ are stronger than that of $\mathrm{MAPbI}_{3}$, which implies that the reaction rate is very fast and $\mathrm{BA}$ treatment may completely convert $\mathrm{MAPbI}_{3}$ into $(\mathrm{BA})_{2} \mathrm{PbI}_{4}$ when the treatment time is long enough. For BAI-treated films, some additional diffraction peaks are also observed. They are indexed to be the (002) plane of $(\mathrm{BA})_{2} \mathrm{PbI}_{4}(n=1),(040)$, (060), (111), (0k0), and (222) planes of 2D perovskites with $n$ $=2$, and (111) and (222) planes of 2D perovskite layer with $n$ $=3,4$, indicating the formation of a $2 \mathrm{D}$ perovskite mixture with different $n$ values.

The optical absorption of pristine, BA-treated, and BAItreated $\mathrm{MAPbI}_{3}$ films with different reaction times was investigated. The UV-vis absorption spectra of the 2D $(\mathrm{BA})_{2}(\mathrm{MA})_{n-1} \mathrm{~Pb}_{n} \mathrm{I}_{3 n+1}$ family $(n=1-4)$ had been previously reported. ${ }^{31}$ The excitonic absorption peaks could be observed at 2.44, 2.17, 2.04, and $1.93 \mathrm{eV}$ for $n=1,2,3$, and 4, respectively. As clearly shown in Figure $2 b$, an additional absorption peak at $2.44 \mathrm{eV}$ was observed in $\mathrm{BA}$-treated $\mathrm{MAPbI}_{3}$ thin films after reaction for $3 \mathrm{~min}$. When the reaction time increased to 5 and $10 \mathrm{~min}$, this absorption peak could still be recognized with the same photon energy. This absorption peak corresponds to the excitonic absorption from 2D perovskite $(\mathrm{BA})_{2} \mathrm{PbI}_{4}(n=1)$, which agrees well with the XRD result in Figure 2a. The UV-vis absorption spectra of BAI-treated $\mathrm{MAPbI}_{3}$ films are shown in Figure 2c; two peaks located at 2.04 and $1.93 \mathrm{eV}$ can be clearly resolved with a reaction time of 3 min, corresponding to the excitonic absorption from 2D perovskites with $n=3$ and 4 , respectively. When the reaction time was increased to $5 \mathrm{~min}$, an extra peak at $2.17 \mathrm{eV}$ showed up, which was located at the same position as the excitonic absorption peak of $2 \mathrm{D}$ perovskites with $n=2$. Upon further increasing the reaction time to $10 \mathrm{~min}$, two high energy peaks $(2.44$ and $2.17 \mathrm{eV})$ stood out, which were indexed to be excitonic absorption from $2 \mathrm{D}$ perovskites with $n=1$ and 2, while two low-energy peaks gradually merged into the continuum absorption spectrum of $3 \mathrm{D}$ perovskites. It is concluded that a mixture of $2 \mathrm{D}$ perovskites with a variety of layer numbers is formed after BAI treatment.

The surfaces of $3 \mathrm{D}$ perovskite films made by a regular solution process have been shown to be defective, while some charge transport materials were found to passivate the surface defects of perovskite films. ${ }^{32,33}$ We speculate that the formation 
of $2 \mathrm{D}$ perovskites may also heal the surface defects due to the conversion of the defective surface of $3 \mathrm{D}$ perovskites into $2 \mathrm{D}$ perovskites. Time-resolved photoluminescence (TRPL) measurement has been conducted to examine the defect passivation effects of BA and BAI treatments on $\mathrm{MAPbI}_{3}$ films. The TRPL measurements revealed an increased carrier lifetime for the $\mathrm{MAPbI}_{3}$ films after both BA and BAI treatments, as shown in Figure 3a,b. The carrier lifetime of the pristine $\mathrm{MAPbI}_{3}$ film was
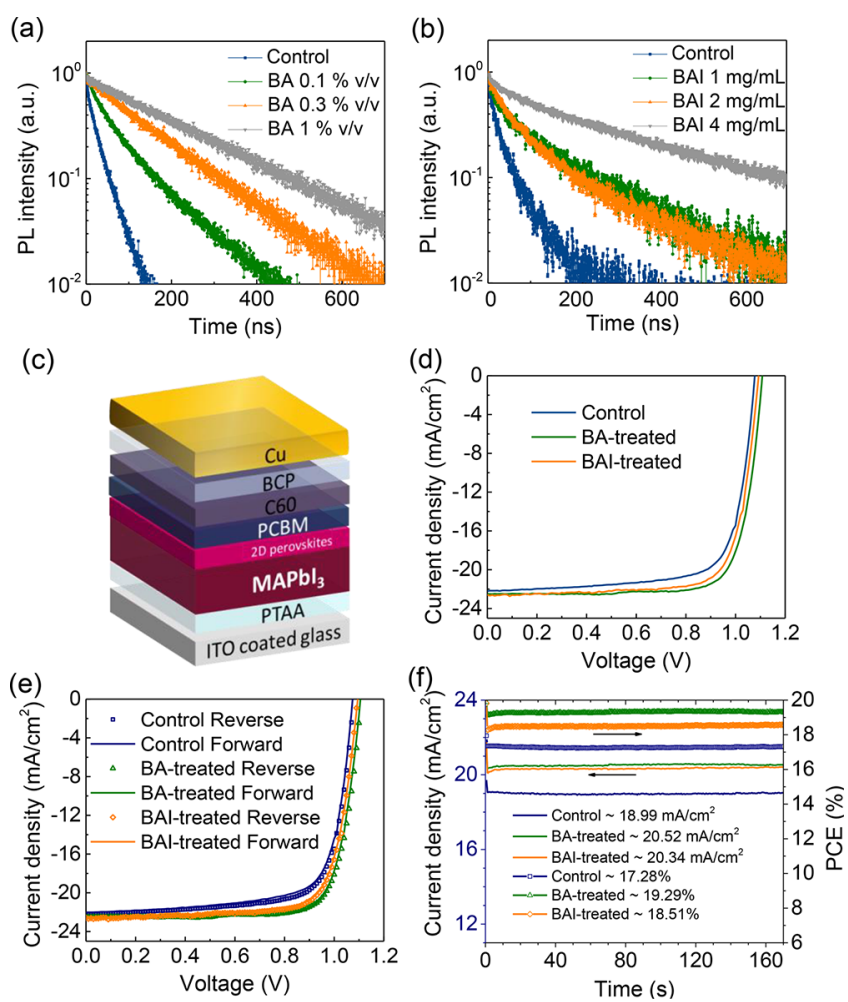

Figure 3. PL decay comparison for control $\left(\mathrm{MAPbI}_{3}\right.$ films $)$ and $\mathrm{BA}-$ treated $\mathrm{MAPbI}_{3}$ films (a) and control and BAI-treated $\mathrm{MAPbI}_{3}$ films (b) with different concentrations; schematic figure of the device structure (c), $J-V$ characteristics for the best cells (d), comparison of forward and reverse scans (e), and maximum power point tracking under continuous 1 sun illumination (f) of the control, BA-treated, and BAI-treated devices.

$16 \mathrm{~ns}$, and after BA treatment, the carrier recombination lifetime was increased to 52, 122, and $204 \mathrm{~ns}$ when increasing the concentration of BA solution for spin-coating to $0.1,0.3$, and $1 \% \mathrm{v} / \mathrm{v}$, respectively. For BAI treatment, when increasing the BAI concentrations to 1,2 , and $4 \mathrm{mg} / \mathrm{mL}$, the carrier lifetime was increased to 48,56 , and 194 ns, respectively.

The photovoltaic devices had a structure of indium tin oxide (ITO)/poly(bis (4-phenyl) (2,4,6-trimethylphenyl)amine) (PTAA)/perovskite/[6,6]-phenyl-C61-butyric acid methyl ester (PCBM)/ $\mathrm{C}_{60} / 2,9$-dimethyl-4,7-diphenyl-1,10-phenanthroline $(\mathrm{BCP}) / \mathrm{Cu}$ (Figure 3c). The photovoltaic performance of devices treated by BA and BAI was optimized with different solution concentrations, and the photocurrent density-voltage $(J-V)$ characteristics are shown in Figure S2a,b, respectively. The detailed device performance parameters are summarized in Table S1. For BA-treated devices, the best device efficiency was achieved with a solution concentration of $0.1 \% \mathrm{v} / \mathrm{v}$. The device efficiency reduced when the concentration was further increased. This is because of the formation of too thick twodimensional perovskites with poor charge transport properties.
For BAI-treated devices, the optimized PCE was obtained with a concentration of $1 \mathrm{mg} / \mathrm{mL}$. Similarly, when the concentration was further increased, the device performance got worse. Figure S3 provides statistical data on the reproducibility of the solar cell performance. Under simulated 1 sun illumination, average efficiencies of $17.05 \%$ (s.d. (standard deviation) \pm 0.30 ), $18.89 \%$ (s.d. \pm 0.34 ), and $18.17 \%$ (s.d. \pm 0.31 ) were obtained from 40 devices for pristine, BA-treated, and BAI-treated $\mathrm{MAPbI}_{3}$, respectively. The detailed statistical data is summarized in Table S2. The $J-V$ curves are shown for the best cells in Figure $3 \mathrm{~d}$ (reverse scan). The substantial improvements in performance produced by BA and BAI treatments are reflected in all photovoltaic metrics (see Table S3). Compared to the control device $\left(J_{\mathrm{sc}}: 22.20 \mathrm{~mA} / \mathrm{cm}^{2} ; V_{\text {oc }}: 1.08 \mathrm{~V}\right.$; FF: 0.74; PCE: $17.75 \%)$, the best device achieved for BA treatment had a $J_{\mathrm{sc}}$ of $22.49 \mathrm{~mA} / \mathrm{cm}^{2}$, a $V_{\text {oc }}$ of $1.11 \mathrm{~V}$, a FF of 0.78 , and a PCE of $19.56 \%$. For BAI-treated devices, the best obtained PCE was $18.85 \%\left(J_{\text {sc }}: 22.59 \mathrm{~mA} / \mathrm{cm}^{2} ; V_{\text {oc }}: 1.09 \mathrm{~V} ;\right.$ FF: 0.77$)$. The $J-V$ characteristics of forward and reverse scanning for the best cells were recorded (Figure 3e), with no obvious hysteresis observed (see Table S4 for detailed photovoltaic parameters). A stable output photocurrent density and PCE of these champion cells were obtained under the standard 1 sun illumination (Figure $3 \mathrm{f})$. Compared to the control device (17.28\%), higher PCEs of 19.29 and $18.51 \%$ were achieved in BA- and BAI-treated devices, respectively.

The capability of $2 \mathrm{D} / 3 \mathrm{D}$ stacking structures toward thermal stress was investigated. Capacitance vs frequency measurement was adopted to investigate the device degradation caused by thermal stress. The spectra of fresh devices and aged devices (heated at $85{ }^{\circ} \mathrm{C}$ for $20 \mathrm{~h}$ ) are displayed in Figure $4 \mathrm{a}, \mathrm{b}$, respectively. For fresh devices, no obvious difference can be observed in the capacitance-frequency spectra. After thermal stress, the device based on $3 \mathrm{D} \mathrm{MAPbI}_{3}$ exhibits nearly 1 order of magnitude larger capacitance than that of the fresh devices in the low-frequency region, while similar capacitance in the high-

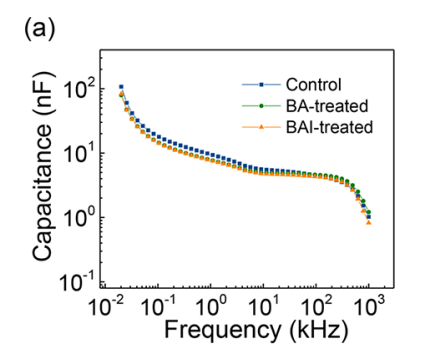

(c)

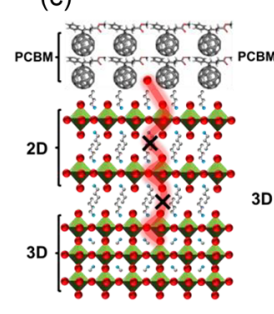

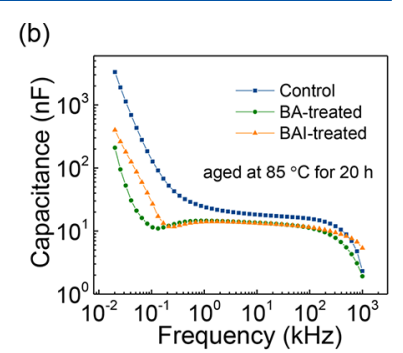

(d)

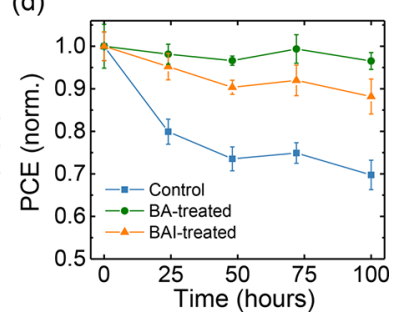

Figure 4. Capacitance-frequency spectra of the control, BA-treated, and BAI-treated devices (a) before and (b) after thermal stress at 85 ${ }^{\circ} \mathrm{C}$ for $20 \mathrm{~h}$; (c) proposed degradation mechanism in 2D/3D stacking and 3D devices; (d) normalized PCE of the related devices in a thermal stress test over time; each point is representative of seven samples. The marker indicates the mean value of each set of data, and the error bars are standard deviations. 
frequency region. The capacitance in the low-frequency regime may be attributed to ionic migration to the contact interface $^{34-36}$ At moderately high temperature, the cationic and halide components in $3 \mathrm{D} \mathrm{MAPbI}$ can easily escape from the surface, producing high-density iodine and MA vacancies in perovskite materials facilitating ionic motion, which results in increased capacitance in the low-frequency regime. This thermal decomposition usually starts from the surface and grain boundaries where there is higher defect density. ${ }^{28}$ As illustrated in Figure 4c, the 2D perovskite layer at the surface and grain boundaries in a $2 \mathrm{D} / 3 \mathrm{D}$ stacking structure could effectively suppress the formation of mobile ions under elevated temperature as compared to $3 \mathrm{D}$ perovskites. In $3 \mathrm{D}$ perovskites, the volatilization of $\mathrm{MA}$ or $\mathrm{I}_{2}$ from the crystal surface or grain boundaries should be the major reason for the formation of mobile MA and iodine vacancies. The larger size of $\mathrm{BA}^{+}$as compared to $\mathrm{MA}^{+}$is supposed to play a key role in stopping the volatilization of $\mathrm{MA}$ or $\mathrm{I}_{2}$. This is because neither the volatilization of the $\mathrm{BA}^{+}$ion itself nor the exchanges of $\mathrm{BA}^{+}$ with inner $\mathrm{MA}^{+}$ions is easy. In our previous publication, we showed that using larger organic cation $\mathrm{BA}^{+}$could increase the ion migration potential barrier, which also helps to suppress the escape of volatile ions from the perovskite crystal. ${ }^{37}$

The stability of the devices was evaluated in an accelerated mode. Because the encapsulated devices last more than 1 month under illumination, here the nonencapsulated devices were evaluated under an elevated temperature of $95{ }^{\circ} \mathrm{C}$ and were compared with control devices. Here, seven devices were tested for each condition. The normalized average PCEs along the testing time are shown in Figure 4d. The control device degraded to $69.8 \%$ of its initial efficiency after continuous heating for $100 \mathrm{~h}$, while the modified devices still maintained 96.5 and $88.2 \%$ of their initial efficiencies for devices with BA and BAI treatments, respectively. The deterioration of device performance agrees quite well with the thermal study observed above. The comparison of normalized $J_{\mathrm{sc}} V_{\mathrm{oc}} \mathrm{FF}$, and PCE of the control, BA-treated, and BAI-treated devices in thermal stability tests is summarized in Figure S4.

In summary, the perovskite solar cells with $2 \mathrm{D} / 3 \mathrm{D}$ stacking structures were achieved by two different post-treatment methods. The compositions of resulting $2 \mathrm{D}$ perovskites are different due to the different chemical reaction mechanisms. However, both perovskite solar cells with 2D/3D stacking structures were demonstrated to be effective in enhancing the device performance by passivation and self-healing effects. Meanwhile, these structures have much better thermal stability than conventional $3 \mathrm{D}$ perovskite solar cells due to the reduced defect density and suppressed ion migration on the surface and at grain boundaries. Our work provides insight on the chemical reaction mechanism of forming $2 \mathrm{D} / 3 \mathrm{D}$ stacking structures and provides a new avenue to tune the $2 \mathrm{D} / 3 \mathrm{D}$ stacking structures by adopting different post-treatments as well as increasing both the performance and stability of perovskite solar cells.

\section{ASSOCIATED CONTENT}

\section{Supporting Information}

The Supporting Information is available free of charge on the ACS Publications website at DOI: 10.1021/acs.jpclett.7b02679.

Experimental section and additional figures and tables showing AFM images, $J-V$ characteristics, photovoltaic performance values and parameters, and statistical analyses and comparisons of the parameters (PDF)

\section{AUTHOR INFORMATION}

\section{Corresponding Author}

*E-mail: jhuang@unc.edu.

ORCID

Yun Lin: 0000-0001-6674-780X

Jinsong Huang: 0000-0002-0509-8778

\section{Notes}

The authors declare no competing financial interest.

\section{ACKNOWLEDGMENTS}

This work was supported by the Office of Naval Research, Grant Number N00014-17-1-2727 and N00014-17-1-2163. Y.L. acknowledges support from the China Scholarship Council.

\section{REFERENCES}

(1) Yang, W. S.; Noh, J. H.; Jeon, N. J.; Kim, Y. C.; Ryu, S.; Seo, J.; Seok, S. I. High Performance Photovoltaic Perovskite Layers Fabricated through Intramolecular Exchange. Science 2015, 348, $1234-1237$.

(2) Xiao, Z.; Kerner, R. A.; Zhao, L.; Tran, N. L.; Lee, K. M.; Koh, T.W.; Scholes, G. D.; Rand, B. P. Efficient Perovskite Light-Emitting Diodes Featuring Nanometre-Sized Crystallites. Nat. Photonics 2017, 11, 108-115.

(3) Shen, L.; Fang, Y.; Wang, D.; Bai, Y.; Deng, Y.; Wang, M.; Lu, Y.; Huang, J. A Self-Powered, Sub-Nanosecond-Response SolutionProcessed Hybrid Perovskite Photodetector for Time-Resolved Photoluminescence-Lifetime Detection. Adv. Mater. 2016, 28, 10794-10800.

(4) Wei, H.; Fang, Y.; Mulligan, P.; Chuirazzi, W.; Fang, H.-H.; Wang, C.; Ecker, B. R.; Gao, Y.; Loi, M. A.; Cao, L.; et al. Sensitive XRay Detectors Made of Methylammonium Lead Tribromide Perovskite Single Crystals. Nat. Photonics 2016, 10, 333-339.

(5) Jeon, N. J.; Noh, J. H.; Yang, W. S.; Kim, Y. C.; Ryu, S.; Seo, J.; Seok, S. I. Compositional Engineering of Perovskite Materials for High-Performance Solar Cells. Nature 2015, 517, 476-480.

(6) Stranks, S. D.; Eperon, G. E.; Grancini, G.; Menelaou, C.; Alcocer, M. J.; Leijtens, T.; Herz, L. M.; Petrozza, A.; Snaith, H. J. Electron-Hole Diffusion Lengths Exceeding 1 Micrometer in An Organometal Trihalide Perovskite Absorber. Science 2013, 342, 341344.

(7) Xing, G.; Mathews, N.; Sun, S.; Lim, S. S.; Lam, Y. M.; Gratzel, M.; Mhaisalkar, S.; Sum, T. C. Long-Range Balanced Electron- and Hole-Transport Lengths in Organic-Inorganic $\mathrm{CH}_{3} \mathrm{NH}_{3} \mathrm{PbI}_{3}$. Science 2013, 342, 344-347.

(8) Azpiroz, J. M.; Mosconi, E.; Bisquert, J.; De Angelis, F. Defect Migration in Methylammonium Lead Iodide and its Role in Perovskite Solar Cell Operation. Energy Environ. Sci. 2015, 8, 2118-2127.

(9) Kim, J.; Lee, S. H.; Lee, J. H.; Hong, K. H. The Role of Intrinsic Defects in Methylammonium Lead Iodide Perovskite. J. Phys. Chem. Lett. 2014, 5, 1312-1317.

(10) De Marco, N.; Zhou, H.; Chen, Q.; Sun, P.; Liu, Z.; Meng, L.; Yao, E. P.; Liu, Y.; Schiffer, A.; Yang, Y. Guanidinium: A Route to Enhanced Carrier Lifetime and Open-Circuit Voltage in Hybrid Perovskite Solar Cells. Nano Lett. 2016, 16, 1009-1016.

(11) Chen, Q.; Zhou, H.; Song, T. B.; Luo, S.; Hong, Z.; Duan, H. S.; Dou, L.; Liu, Y.; Yang, Y. Controllable Self-Induced Passivation of Hybrid Lead Iodide Perovskites toward High Performance Solar Cells. Nano Lett. 2014, 14, 4158-4163.

(12) Li, X.; Dar, M. I.; Yi, C.; Luo, J.; Tschumi, M.; Zakeeruddin, S. M.; Nazeeruddin, M. K.; Han, H.; Gratzel, M. Improved Performance and Stability of Perovskite Solar Cells by Crystal Crosslinking with Alkylphosphonic Acid Omega-Ammonium Chlorides. Nat. Chem. 2015, 7, 703-711.

(13) Son, D.-Y.; Lee, J.-W.; Choi, Y. J.; Jang, I.-H.; Lee, S.; Yoo, P. J.; Shin, H.; Ahn, N.; Choi, M.; Kim, D.; et al. Self-Formed Grain 
Boundary Healing Layer for Highly Efficient $\mathrm{CH}_{3} \mathrm{NH}_{3} \mathrm{PbI}_{3}$ Perovskite Solar Cells. Nat. Energy 2016, 1, 16081.

(14) Abate, A.; Saliba, M.; Hollman, D. J.; Stranks, S. D.; Wojciechowski, K.; Avolio, R.; Grancini, G.; Petrozza, A.; Snaith, H. $\mathrm{J}$. Supramolecular Halogen Bond Passivation of Organic-Inorganic Halide Perovskite Solar Cells. Nano Lett. 2014, 14, 3247-3254.

(15) Noel, N. K.; Abate, A.; Stranks, S. D.; Parrott, E. S.; Burlakov, V. M.; Goriely, A.; Snaith, H. J. Enhanced Photoluminescence and Solar Cell Performance via Lewis Base Passivation of Organic-Inorganic Lead Halide Perovskites. ACS Nano 2014, 8, 9815-9821.

(16) Ahn, N.; Son, D. Y.; Jang, I. H.; Kang, S. M.; Choi, M.; Park, N. G. Highly Reproducible Perovskite Solar Cells with Average Efficiency of $18.3 \%$ and Best Efficiency of $19.7 \%$ Fabricated via Lewis Base Adduct of Lead(II) Iodide. J. Am. Chem. Soc. 2015, 137, 8696-8699.

(17) Zhao, T.; Chueh, C.-C.; Chen, Q.; Rajagopal, A.; Jen, A. K. Y. Defect Passivation of Organic-Inorganic Hybrid Perovskites by Diammonium Iodide toward High-Performance Photovoltaic Devices. ACS Energy Lett. 2016, 1, 757-763.

(18) Bi, D.; Gao, P.; Scopelliti, R.; Oveisi, E.; Luo, J.; Gratzel, M.; Hagfeldt, A.; Nazeeruddin, M. K. High-Performance Perovskite Solar Cells with Enhanced Environmental Stability Based on AmphiphileModified $\mathrm{CH}_{3} \mathrm{NH}_{3} \mathrm{PbI}_{3}$. Adv. Mater. 2016, 28, 2910-2915.

(19) Wang, F.; Geng, W.; Zhou, Y.; Fang, H. H.; Tong, C. J.; Loi, M. A.; Liu, L. M.; Zhao, N. Phenylalkylamine Passivation of Organolead Halide Perovskites Enabling High-Efficiency and Air-Stable Photovoltaic Cells. Adv. Mater. 2016, 28, 9986-9992.

(20) Yang, S.; Wang, Y.; Liu, P.; Cheng, Y.-B.; Zhao, H. J.; Yang, H. G. Functionalization of Perovskite Thin Films with Moisture-Tolerant Molecules. Nat. Energy 2016, 1, 15016.

(21) National Renewable Energy Laboratory. Research Cell Record Efficiency Chart. https://www.nrel.gov/pv/assets/images/efficiencychart.png (accessed Oct. 1, 2017).

(22) Smith, I. C.; Hoke, E. T.; Solis-Ibarra, D.; McGehee, M. D.; Karunadasa, H. I. A Layered Hybrid Perovskite Solar-Cell Absorber with Enhanced Moisture Stability. Angew. Chem., Int. Ed. 2014, 53, 11232-11235.

(23) Cao, D. H.; Stoumpos, C. C.; Farha, O. K.; Hupp, J. T.; Kanatzidis, M. G. 2D Homologous Perovskites as Light-Absorbing Materials for Solar Cell Applications. J. Am. Chem. Soc. 2015, 137, $7843-7850$.

(24) Tsai, H.; Nie, W.; Blancon, J. C.; Stoumpos, C. C.; Asadpour, R.; Harutyunyan, B.; Neukirch, A. J.; Verduzco, R.; Crochet, J. J.; Tretiak, S.; et al. High-Efficiency Two-Dimensional RuddlesdenPopper Perovskite Solar Cells. Nature 2016, 536, 312-316.

(25) Quan, L. N.; Yuan, M.; Comin, R.; Voznyy, O.; Beauregard, E. M.; Hoogland, S.; Buin, A.; Kirmani, A. R.; Zhao, K.; Amassian, A.; et al. Ligand-Stabilized Reduced-Dimensionality Perovskites. J. Am. Chem. Soc. 2016, 138, 2649-2655.

(26) Yao, K.; Wang, X.; Xu, Y.-x.; Li, F.; Zhou, L. Multilayered Perovskite Materials Based on Polymeric-Ammonium Cations for Stable Large-Area Solar Cell. Chem. Mater. 2016, 28, 3131-3138.

(27) Zhang, X.; Ren, X. D.; Liu, B.; Munir, R.; Zhu, X. J.; Yang, D.; Li, J. B.; Liu, Y. C.; Smilgies, D. M.; Li, R. P.; et al. Stable High Efficiency Two-Dimensional Perovskite Solar Cells via Cesium Doping. Energy Environ. Sci. 2017, 10, 2095-2102.

(28) Wang, Q.; Chen, B.; Liu, Y.; Deng, Y.; Bai, Y.; Dong, Q.; Huang, J. Scaling Behavior of Moisture-Induced Grain Degradation in Polycrystalline Hybrid Perovskite Thin Films. Energy Environ. Sci. 2017, 10, 516-522.

(29) Zhou, Z.; Wang, Z.; Zhou, Y.; Pang, S.; Wang, D.; Xu, H.; Liu, Z.; Padture, N. P.; Cui, G. Methylamine-Gas-Induced Defect-Healing Behavior of $\mathrm{CH}_{3} \mathrm{NH}_{3} \mathrm{PbI}_{3}$ Thin Films for Perovskite Solar Cells. Angew. Chem., Int. Ed. 2015, 54, 9705-9709.

(30) Yang, S.; Zheng, Y. C.; Hou, Y.; Chen, X.; Chen, Y.; Wang, Y.; Zhao, H.; Yang, H. G. Formation Mechanism of Freestanding $\mathrm{CH}_{3} \mathrm{NH}_{3} \mathrm{PbI}_{3}$ Functional Crystals: In Situ Transformation vs Dissolution-Crystallization. Chem. Mater. 2014, 26, 6705-6710.

(31) Liu, J.; Leng, J.; Wu, K.; Zhang, J.; Jin, S. Observation of Internal Photoinduced Electron and Hole Separation in Hybrid Two-
Dimentional Perovskite Films. J. Am. Chem. Soc. 2017, 139, 14321435.

(32) Fang, Y.; Bi, C.; Wang, D.; Huang, J. The Functions of Fullerenes in Hybrid Perovskite Solar Cells. ACS Energy Lett. 2017, 2, 782-794.

(33) Shao, Y.; Xiao, Z.; Bi, C.; Yuan, Y.; Huang, J. Origin and Elimination of Photocurrent Hysteresis by Fullerene Passivation in $\mathrm{CH}_{3} \mathrm{NH}_{3} \mathrm{PbI}_{3}$ Planar Heterojunction Solar Cells. Nat. Commun. 2014, $5,5784$.

(34) Hoque, M. N. F.; Yang, M.; Li, Z.; Islam, N.; Pan, X.; Zhu, K.; Fan, Z. Polarization and Dielectric Study of Methylammonium Lead Iodide Thin Film to Reveal its Nonferroelectric Nature under Solar Cell Operating Conditions. ACS Energy Lett. 2016, 1, 142-149.

(35) Jonscher, A. Analysis of the Alternating Current Properties of Ionic Conductors. J. Mater. Sci. 1978, 13, 553-562.

(36) Lin, Q.; Armin, A.; Nagiri, R. C. R.; Burn, P. L.; Meredith, P. Electro-Optics of Perovskite Solar Cells. Nat. Photonics 2015, 9, 106112.

(37) Lin, Y.; Bai, Y.; Fang, Y.; Wang, Q.; Deng, Y.; Huang, J. Suppressed Ion Migration in Low-Dimensional Perovskites. ACS Energy Lett. 2017, 2, 1571-1572. 